\title{
Childhood Herpes Zoster-Triggered Guttate Psoriasis
}

\author{
V. Failla, N. Nikkels-Tassoudji, M. Sabatiello, V. de Schaetzen and A.F. Nikkels*
}

Department of Dermatology, University Hospital of Liège, Liège, Belgium

\begin{abstract}
Psoriasis is commonly triggered or exacerbated by various stress factors, certain drugs, or streptococcal throat infections. Viral infections such as HIV, CMV, chikungunya, or herpes simplex virus are very uncommon triggers for psoriasis. Cases of varicella-triggered psoriasis are exceptional. A 7-year-old boy with a previous history of guttate psoriasis presented with generalized acute guttate psoriasis shortly after an extensive herpes zoster infection affecting the first and second left lumbar dermatomes. INF-alpha and granulocyte monocyte colony stimulating factor influence peripheral monocytes to transform into INF-dendritic cells (DC's), similar to those involved in psoriasis. These INF-DC's express toll-like receptors 7 and 8 , which are responsive to viral single stranded RNA. Hence, viral infections and interferon (INF)-alpha may play a role in triggering psoriasis.
\end{abstract}

A PubMed search revealed no previous reports of herpes zoster triggered acute guttate psoriasis in children.

Keywords: Herpes zoster, varicella zoster virus, psoriasis, child.

\section{INTRODUCTION}

Psoriasis, especially acute guttate psoriasis and plaque psoriasis, may be induced or exacerbated by a variety of trigger factors which may also impair the treatment response. The most common trigger is stress [1], probably mediated by a hypothalamic-pituitary-adrenal relationship with immunologic events. Medications such as lithium, beta blocking agents, or acetylsalicylic acid may also be involved [2-4]. However, the degree to which a drug may be responsible is not always easy to determine [2-5]. Smoking and alcohol abuse may also promote the development of psoriasis [6]. Furthermore, various infectious agents can trigger or aggravate psoriasis. The most common are betahemolytic streptococcal throat infections that can provoke acute guttate psoriasis or exacerbate preexisting plaque psoriasis $[7,8]$. Induction/exacerbation of psoriasis following viral infections is less common. Chikungunya infection [9], HIV/AIDS [10], persistent CMV infection [11] and herpes simplex virus (HSV)-related erythema multiforme [12] have all been reported as causal and/or aggravating factors. Acute guttate psoriasis in young children may also be seen after upper respiratory tract viral infections in connection with measles or influenza. Three publications have reported acute guttate psoriasis following varicella zoster virus (VZV) infections [13-15].

A PubMed search did not identify any previous reports of acute generalized guttate psoriasis following herpes zoster (HZ) in a child.

\section{CASE REPORT}

A 7-year-old boy without any significant medical history presented with an unilateral inguinal vesicular eruption (Fig. 1). The boy was not taking any medication and had no atopic

*Address correspondence to this author at the Department of Dermatology, CHU of Sart Tilman, University of Liège, B-4000 Liège, Belgium; Tel: +32-43667232; Fax: +32-43667234; E-mail: af.nikkels@chu.ulg.ac.be

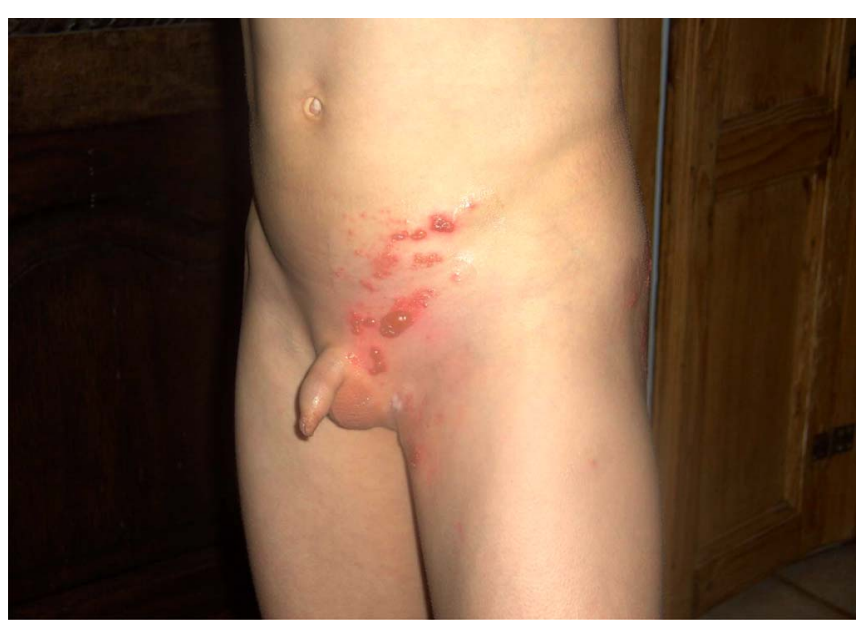

Fig. (1). Herpes zoster in the left anterior L1 and L2 dermatomes, vesicular stage.

background. There was no family history of psoriasis. Vaccination status was assessed in accordance with local health regulations. The child had not been vaccinated against varicella. At the age of 1 he had presented with moderate varicella. Two years prior to the present consultation he had presented with acute generalized guttate psoriasis following a beta-hemolytic streptococcal throat infection. The lesions were clustered and scattered in a dermatomal distribution (L1, L2) and were almost perfectly semicircular in shape (Fig. 2). All elements were vesicular. One week before the lesions appeared, the child had been complaining of burning and stinging pains in the inguinal area, prompting his mother to administer paracetamol. The child was not feverish and no lymph nodes were identified on physical examination. The typical unilateral distribution of the skin lesions and the presence of prodromal pains suggested the diagnosis of inguinal childhood HZ. A Tzanck smear was performed on one of the vesicular lesions and stained with PMS 


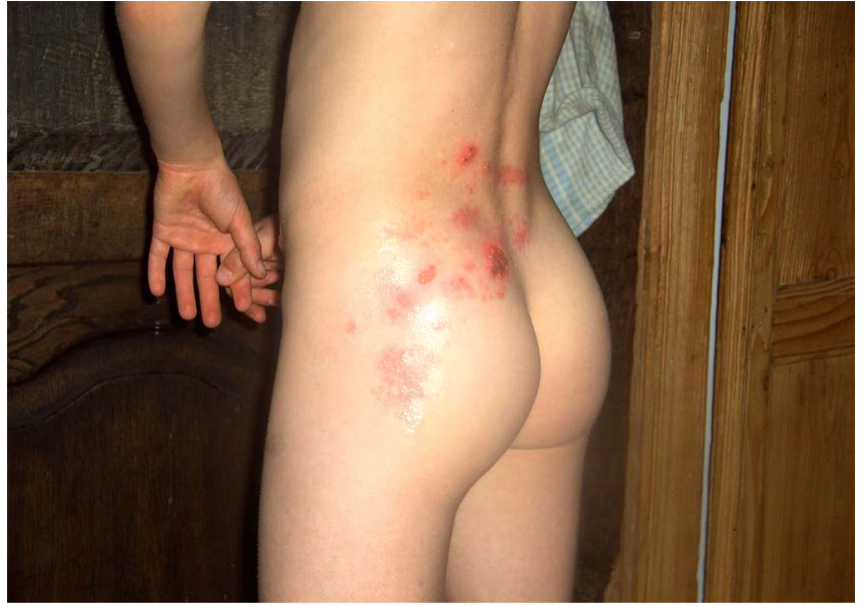

Fig. (2). Herpes zoster in the left posterior L1 and L2 dermatomes, vesicular stage.

(Polychrome Multiple Stain); this revealed syncitial giant cells, suggestive of an alpha-herpesvirus infection. Immunohistochemistry revealed the presence of the VZVspecific surface glycoprotein $\mathrm{gE}$, whereas no HSV glycoproteins were detected [16]. As antiviral treatment is not recommended for $\mathrm{HZ}$ in children [17], the boy received only paracetamol $250 \mathrm{mg}$ twice daily as supportive treatment. The pain was gradually alleviated and progressively disappeared over two weeks, with a simultaneous resolution of the skin lesions. One week later, the child represented to the dermatologist as he had rapidly developed an eruption of small erythematous and squamous well-circumscribed lesions over the entire body, suggestive of generalized acute guttate psoriasis (Fig. 3). The child did not show any signs of a throat infection and had no fever, and no locoregional lymphadenopathies were palpated. The tonsils were neither swollen nor erythematous. A blood sample showed no evidence of any significant changes.

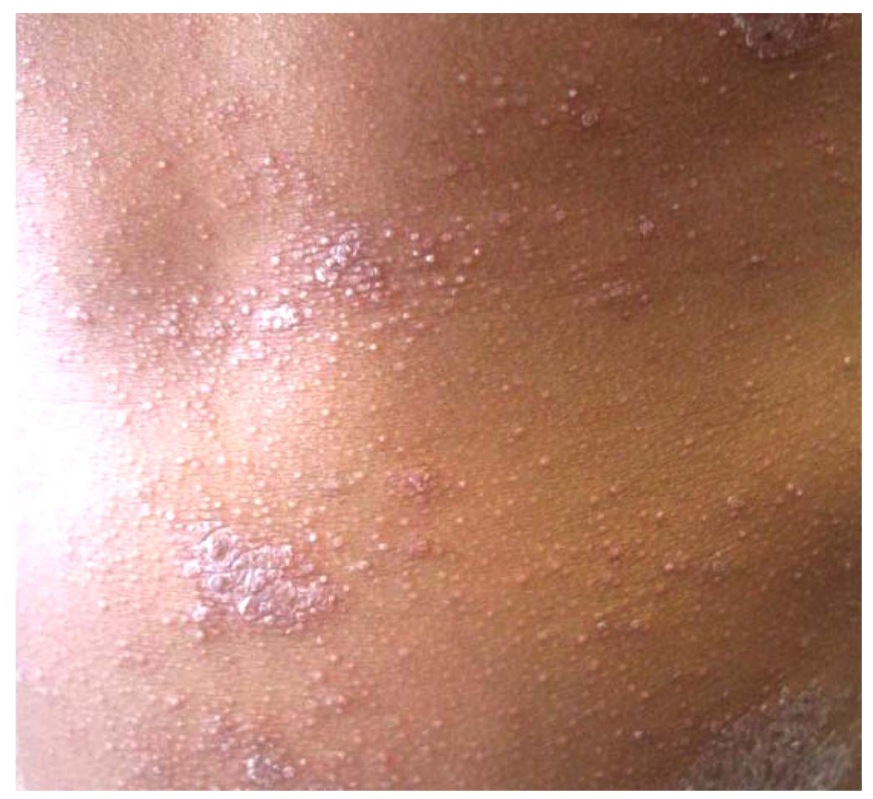

Fig. (3). Acute generalized guttate psoriasis.
Hepatic and renal function were both normal. The Antistreptolysin-O (ASLO) titer was negative, as was a throat culture. Topical application of potent corticosteroids (betamethasone dipropionate $0,05 \%$ cream, $1 \mathrm{x} / \mathrm{d}, 15$ days) was commenced. The psoriasis lesions progressively resolved over approximately 3 weeks. The child showed no signs of any persisting post-zoster neuralgia, nor of any residual scarring from the cutaneous lesions.

\section{DISCUSSION}

Acute guttate psoriasis is a distinctive acute form of psoriasis that typically occurs in children and young adults. It is commonly associated with antecedent streptococcal throat infection or tonsillitis [7,8]. A study performed polymerase chain reaction (PCR) assays to detect universal $16 \mathrm{~S}$ ribosomal DNA primers and specific primers for Streptococcus pyogenes in peripheral blood samples from 7 patients with guttate psoriasis, 6 patients with chronic plaque psoriasis, 7 chronic plaque psoriasis patients with associated guttate psoriasis, and 16 controls. Ribosomal bacterial DNA was found in all the psoriasis patients but not in the control group. Streptococci were found in 6 of 7 guttate psoriasis patients, whereas Staphylococci were identified in 9 of 13 patients with chronic plaque psoriasis. These findings suggest that distinct taxonomic bacterial groups are present in guttate and chronic plaque psoriasis [18]. Evidence of T cells recognizing common determinants to streptococcal Mprotein and keratin have been found in psoriasis patients. CD8 $+\mathrm{T}$ cells in psoriatic epidermis respond mainly to such determinants, whereas CD4+ $\mathrm{T}$ cells in the dermis preferentially recognize determinants of the streptococcal peptidoglycan that might act as adjuvants [19]. A comparative one-year observational study showed that psoriasis patients reported having a sore throat significantly more often than controls $(61 / 208$ vs $3 / 116, \mathrm{P}<0.0001)$, and beta-hemolytic Streptococci of Lancefield groups A, C and G (M protein-positive Streptococci) were significantly more frequently cultured from the patients than the controls (19 of $208 v s$ one of $116, \mathrm{P}=0.003$ ) (8). Despite the clear relationship between the streptococcal infection and recurrent acute guttate psoriasis or chronic plaque psoriasis, there is currently no evidence that antibiotics and/or tonsillectomy are beneficial for these patients [7]. Psoriasis has also been described after throat infections by Candida albicans [20].

Viral infections leading to acute guttate psoriasis are rarely reported and the pathomechanisms have not been elucidated (Table 1). Some of the reported infections, including measles, influenza and HSV-related erythema multiforme [12] are localized in the throat, similar to Streptococcal infections. In contrast, Chikungunya infection [9], human immunodeficiency virus (HIV) infection [10], and persistent CMV infection [11] are systemic viral infections. Other authors have not been able to establish a link between CMV or human herpes viruses (HHV) 6 and 7 infections and a subsequent development of psoriasis [21]. HPV subtypes 5 and 36 are also pathogenic candidates, although their precise contribution remains to be clarified [22]. Three publications reported guttate psoriasis following varicella [13-15]. After the initial exposure to VZV, there is a phase of viral replication in the oropharyngeal area. These 
data suggest that bacterial, fungal or viral infections of the throat may play an important role in triggering psoriasis.

Table 1. Potential Infectious Agents Contributing to the Induction or Exacerbation of Psoriasis, or to Treatment Resistance

\begin{tabular}{|c|c|c|}
\hline Risk Factors & Agents & References \\
\hline \hline \multirow{2}{*}{ Bacterial } & Streptococcus & {$[7,8]$} \\
& Staphylococcus & \\
\hline \multirow{2}{*}{ Viral } & HSV-related erythema multiforme & {$[12]$} \\
& VZV & {$[13-15$, this report] } \\
& CMV & {$[11]$} \\
& HIV & {$[10]$} \\
& HPV & {$[22]$} \\
& Influenza & {$[28]$} \\
& Measles & {$[9]$} \\
& Chikungunya & {$[20]$} \\
\hline Fungal & Candidosis & \\
\hline
\end{tabular}

$\mathrm{HZ}$ in children is uncommon but is probably underrecognized [17]. This child presented with chickenpox at the age of 1 , which is a typical risk factor for childhood HZ. As far as we know, this is the first report of a child presenting with $\mathrm{HZ}$ followed by acute guttate psoriasis. Negative ASLO and the absence of drug intake ruled out any other potential triggers of acute guttate psoriasis. The extension and severity of the skin lesions suggest that an associated VZV-viremia was present, which may have played a role in the triggering of the psoriasis. Viral infections and interferon (IFN)-alpha play a role in triggering dendritic cell populations in psoriasis [23]. In fact, under the influence of INF-alpha and granulocyte monocyte colony stimulating factor (GM-CSF), peripheral monocytes transform into INF-dendritic cells (DC's) similar to those involved in psoriasis pathogenesis. The INF-DC's express a large range of toll-like receptors (TLR's) including TLR 7 and 8, responsive to (viral) single stranded RNA (ssRNA). In culture conditions, incubation with ssRNA increased the IFN-DCs mRNAs for interleukin (II) IL-12p35, IL-12p40, IL-23p19, IL-27p28 and IL-27EBI [23]. Hence, viral infections may potentially trigger psoriasis [23]. Whether a similar molecular resemblance exists between some VZV constituents and epidermal keratins to that observed for streptococci, remains to be determined.

This phenomenon has to be distinguished from psoriasis lesions induced by a Koebner phenomenon after varicella skin lesions, which are defined as psoriasis lesions limited and restricted to the sites of previous varicella lesions [2428].

In conclusion, HZ should be added to the list of potential triggers of generalized acute guttate psoriasis.

\section{ACKNOWLEDGEMENT}

Declared none.

\section{CONFLICT OF INTEREST}

Declared none.

\section{REFERENCES}

[1] Basavaraj KH, Navya MA, Rashmi R. Stress and quality of life in psoriasis: an update. Int J Dermatol 2011; 50: 783-92.

[2] Wolf R, Ruocco V. Triggered psoriasis. Adv Exp Med Biol 1999; 455: 221-5.

[3] Tsankov N, Angelova I, Kazandjieva J. Drug-induced psoriasis. Recognition and management. Am J Clin Dermatol 2000; 1: 15965.

[4] Basavaraj KH, Ashok NM, Rashmi R, Praveen TK. The role of drugs in the induction and/or exacerbation of psoriasis. Int $\mathrm{J}$ Dermatol 2010; 49: 1351-61.

[5] Herman SM, Shin MH, Holbrook A, Rosenthal D. The role of antimalarials in the exacerbation of psoriasis: a systematic review. Am J Clin Dermatol 2006; 7: 249-57.

[6] Armstrong AW, Armstrong EJ, Fuller EN, Sockolov ME, Voyles SV. Smoking and Pathogenesis of Psoriasis: A Review of Oxidative, Inflammatory, and Genetic Mechanisms. Br J Dermatol 2011; 165(6): 1162-8

[7] Owen CM, Chalmers RJ, O'Sullivan T, Griffiths CE. Antistreptococcal interventions for guttate and chronic plaque psoriasis. Cochrane Database Syst Rev 2000;(2):CD001976.

[8] Gudjonsson JE, Thorarinsson AM, Sigurgeirsson B, Kristinsson $\mathrm{KG}$, Valdimarsson $\mathrm{H}$. Streptococcal throat infections and exacerbation of chronic plaque psoriasis: a prospective study. Br J Dermatol 2003; 149: 530-4.

[9] Seetharam KA, Sridevi K. Chikungunya infection: A new trigger for psoriasis. J Dermatol 2011; 38: 1033-4.

[10] Blanco González OA, Larrondo Muguercia RJ, Blanco González BL, Rodríguez Barreras ME. Psoriasis and AIDS: a report of 2 cases. Rev Cubana Med Trop 2000; 52: 148-9.

[11] Weitz M, Kiessling C, Friedrich M, et al. Persistent CMV infection correlates with disease activity and dominates the phenotype of peripheral CD8+ T cells in psoriasis. Exp Dermatol 2011; 20: 5617.

[12] Wiemers S, Krutmann J, Kapp A, Schöpf E. Postherpetic erythema exsudativum multiforme with concomitant exacerbation of psoriasis vulgaris. Hautarzt 1990; 41: 506-8.

[13] Ito T, Furukawa F. Psoriasis guttate acuta triggered by varicella zoster virus infection. Eur J Dermatol 2000; 10: 226-7.

[14] Veraldi S, Lunardon L, Dassoni F. Guttate psoriasis triggered by chickenpox. G Ital Dermatol Venereol 2009; 144: 501-2.

[15] Hellgren L. A statistical, clinical and laboratory investigation of 255 psoriatics and matched healthy controls. Acta Derma Venereol (Stockh) 1964; 44: 191-207.

[16] Nikkels AF, Debrus S, Sadzot-Delvaux C, Piette J, Rentier B, Piérard GE. Immunohistochemical identification of varicella-zoster virus gene 63-encoded protein (IE63) and late (gE) protein on smears and cutaneous biopsies: implications for diagnostic use. J Med Virol 1995; 47: 342-7.

[17] Nikkels AF, Nikkels-Tassoudji N, Piérard GE. Revisiting childhood herpes zoster. Pediatr Dermatol 2004; 21: 18-23.

[18] Munz OH, Sela S, Baker BS, Griffiths CE, Powles AV, Fry L. Evidence for the presence of bacteria in the blood of psoriasis patients. Arch Dermatol Res 2010; 302: 495-8.

[19] Valdimarsson H, Thorleifsdottir RH, Sigurdardottir SL, Gudjonsson JE, Johnston A. Psoriasis as an autoimmune disease caused by molecular mimicry. Trends Immunol 2009; 30: 494-501.

[20] Waldman A, Gilhar A, Duek L, Berdicevsky I. Incidence of Candida in psoriasis--a study on the fungal flora of psoriatic patients. Mycoses 2001; 44: 77-81.

[21] Kirby B, Al-Jiffri O, Cooper RJ, Corbitt G, Klapper PE, Griffiths $\mathrm{CE}$. Investigation of cytomegalovirus and human herpes viruses 6 and 7 as possible causative antigens in psoriasis. Acta Derm Venereol 2000; 80: 404-6.

[22] Cronin JG, Mesher D, Purdie K, et al. Beta-papillomaviruses and psoriasis: an intra-patient comparison of human papillomavirus carriage in skin and hair. Br J Dermatol 2008; 159: 113-9.

[23] Farkas A, Tonel G, Nestle FO. Interferon-alpha and viral triggers promote functional maturation of human monocyte-derived dendritic cells. Br J Dermatol 2008; 158: 921-9.

[24] Skory L, Shearn MA. Psoriatic arthritis induced by varicella. West J Med 1979; 131: 440-1

[25] Abraham A, Farber EM. The Köbner response to varicella in psoriasis. Int J Dermatol 1993; 32: 919-20. 
[26] Varaldi S, Rizzitelli G. Varicella, Köbner phenomenon, and psoriasis. Int J Dermatol 1994; 33: 673-4.

[27] Kokolakis GP, Ioannidou D, Cholongitas E, Krüger-Krasagakis S. Guttate psoriasis occurring on varicella lesions. J Dermatol 2010; 37: 857-9.
[28] Müller H, Fäh J, Dummer R. Unusual Koebner phenomenon in psoriasis caused by varicella and UVB. Hautarzt 1997; 48: 130-2

Received: November 22, 2011

Revised: January 21, 2012

Accepted: January 30, 2012

(C) Failla et al.; Licensee Bentham Open.

This is an open access article licensed under the terms of the Creative Commons Attribution Non-Commercial License (http: //creativecommons.org/licenses/by$\mathrm{nc} / 3.0 /$ ) which permits unrestricted, non-commercial use, distribution and reproduction in any medium, provided the work is properly cited. 